\title{
Analysis of the Effects of Botulinum Toxin Type A to Promote the Survival of Transverse Rectus Abdominis Myocutaneous Flaps in an Animal Model
}

\author{
Erika Otilia Haro García ${ }^{1}$, Edna M. Aizpuru², Jorge Eduardo Gutierrez Salgado ${ }^{3}$, \\ Maria Irene Rivera Salgado4, Jose Telich Vidal5, Olin Carrasco Ortiz ${ }^{1}$
}

\author{
${ }^{1}$ Department of Plastic and Reconstructive Surgery at Hospital Angeles del Pedregal, Mexico City, Mexico \\ ${ }^{2}$ Department of Plastic and Reconstructive Surgery at PEMEX Hospital, Facultad Mexicana de Medicina, Universidad la Salle, \\ Mexico City, Mexico \\ ${ }^{3}$ Facultad Medicina UNAM, Mexico City, Mexico \\ ${ }^{4}$ Department of Pathology in Pemex Hospital, Mexico City, Mexico \\ ${ }^{5}$ Facultad Mexicana de Medicina, Universidad la Salle, Mexico City, Mexico \\ Email: erikaharo@yahoo.com, edna_aizpuru@hotmail.com, jorge.eduardo.gutierrez@pemex.com, \\ maria.irene.rivera@pemex.com, jtelich@prodigy.net.mx,plastiksurg@icloud.com
}

How to cite this paper: García, E.O.H. Aizpuru, E.M., Salgado, J.E.G., Salgado, M.I.R., Vidal, J.T. and Ortiz, O.C. (2020) Analysis of the Effects of Botulinum Toxin Type A to Promote the Survival of Transverse Rectus Abdominis Myocutaneous Flaps in an Animal Model. Journal of Biosciences and Medicines, 8, 63-73.

https://doi.org/10.4236/jbm.2020.810007

Received: August 19, 2020

Accepted: October 17, 2020

Published: October 20, 2020

Copyright $\odot 2020$ by author(s) and Scientific Research Publishing Inc. This work is licensed under the Creative Commons Attribution International License (CC BY 4.0).

http://creativecommons.org/licenses/by/4.0/ (c) (i) Open Access

\begin{abstract}
The transverse rectus abdominis myocutaneous (TRAM) flap is one of the techniques for breast reconstruction surgery and other defects. Assuring the vascular input is the main factor that it should be ensured for the survival of the fap. Objective: The article presented is an experimental study, with the objective of evaluating the effect of the vasculature on the myocutaneous flaps of the abdominal rectum with botulinum toxin type A (TBoA) thay may improve the survival of the tissue by promoting the blood perfusion in distal parts of the flap and diminish the risk of necrosis. Material and methods: A total of 30 Wistar male rats, dissect pedicled right TRAM flap in all rats, divided into three groups: Group 1 was applied in saline solution $0.9 \%$; Group 2 was applied in pre surgically TBoA (1 week before lifting the flap); Group 3, will apply TBOA Trans surgical. Results: Histological analysis showed: increased vascularity in group 2 TBoA compared with the saline solution with $\mathrm{P}$ $<0.05$ statistically significant. In terms of fibrosis, inflammation and granulation tissue, there was no statistically significant difference at $\mathrm{p}=0.6$. Muscle atrophy was higher in the group of TBoA in the saline group $\mathrm{p}<0.05$. It was concluded that botulinum toxin type A prevents vasoconstriction of the vessel and promotes vasodilation subsequently lifting the muscle flap, no complications were observed in the groups with TBoA so it can be considered a safe
\end{abstract}


substace and can be used for further studies.

\section{Keywords}

Botulinum Toxin, Tranverse Rectus Abdominis Myocutaneos Flap, Vasodilatation, Survival

\section{Introduction}

The TRAM flap (Transverse Rectus abdominis myocutaneous) still remains a very useful and popular method of breast reconstruction [1]. Performing it in conventional manner, with pedicle, has a relatively high incidence of complications, from which fat necrosis is the most common [2]. This potential vascular compromise is even higher in certain populations, such as in obese patients, smokers, hypertensive, patients with vasculitis or the ones receiving radiotherapy treatment [3]. To reduce the rate of complications, especially in high risk patients, the surgical delay of the flap linking one of its vascular pedicles, the deep epigastric inferior artery [4], cutting the skin territory randomly was considered for a while [1]. Later, it was abandoned by the introduction of variations to the conventional technique. Thus there have been several changes in the technique, trying to improve the blood supply and overcome such problems. One technique includes elevating the contralateral rectus muscle, increasing weakness in the abdominal wall and the consequent possibility of hernia [5]. Performing the transfer of TRAM as a free flap using its dominant pedicle and/or super-charging the flap with a second vascular source by means of a microvascular anastomosis, is another method well described to enhance survival of the skin island, although this technique requires a plastic surgeon with training and experience in microsurgery [6].

The delay of TRAM flap is a technique designed to increase survival of skin extension randomly. Chemical delay would then have the overall benefit of a delay, with the advantage of being a simpler [7], less invasive procedure, and without the surgical risks of surgical delay [8]. That is how several substances have already been used, most of them injected or applied peri vascular or endovascular in order to cause a localized and controlled delay phenomenon, which means, only affecting the delimited area to the flap and that does not cause systemic effects. But so far, a substance that is $100 \%$ safe to use without having systemic effects has not been found [2].

In recent years there has been a significant and satisfactory progress with the use of botulinum toxin type A in many both aesthetic and medical aspects [9], such as reconstructive and functional, which has led to explore further their mechanisms of action finding effects of interest in clinical application [10].

Lately, research of the possible effect of botulinum toxin on muscle blood perfusion, in glucose metabolism, in its relationship with the release of substance P, glutamate, Fos (a product of c-fos) and calcitonin [11] has been widespread. 
Possibly, by this way, its ability to improve the feasibility using it as a delay mechanism, diminishing the myocutaneous resistance of expanding flaps, improving the expansion area, the speed of the inflammatory process and reducing contraction of the myocutaneous flap [11] has been raised.

Progress in vasospastic disorder cases (Raynaud phenomenon specifically) have also been described, where the botulinum toxin may be an alternative treatment; patients have presented improvement by blocking the release of acetylcholine with this product. The smooth muscle of arteries is innervated by sympathetic fibers that use norepinephrine in the synaptic transmission mechanism; botulinum toxin would present a double action [12]: inhibiting vasospasm by blocking the vasoconstriction produced by cold and preventing recruitment of $\alpha 2$ receptors at vascular smooth muscle level.

It has also been reported the usefulness of this therapy for the treatment of ulcers in digits of ischemic origin and in the carpal tunnel trapping syndrome [13] [14].

Based on the principle of calcitonin peptide release, a potent vasodilator, effect attributed to the botulinum toxin, it has been proposed prevention of vascular thrombosis on vascular anastomosis, which occurs in most of cases in the two first days after surgery. With the application of botulinum toxin experimentally, it has been shown that the diameter of anastomosing arterial vessels, in cases where $(0.68 \pm 0.2 \mathrm{~mm})$ was applied was higher than in the cases of the control group $(0.53 \pm 0.02 \mathrm{~mm}), \mathrm{p}<0.001$, and even less difficulty for anastomosis [15] is reported.

Against this background, we have based our hypothesis, to show that TBoA can work as a substance that promotes a phenomenon of non-surgical delay in the TRAM flap, improving survival and increasing the amount of viable tissue in areas most prone to necrosis for being more distal to the pedicle in this case, Hartrampf's zones III and IV.

\section{Material and Methods}

Sample size is calculated by comparing independent means using the EPIDAT 3.1 program (Epidemiological Analysis of Tabulated Data, Xunta de Galicia and PAHO-WHO. 2006) with a confidence level of 95\%; In this way, a sample of 30 rats was determined. 30 Wistar rats between 250 to 300 grams, from 3 to 12 months old are evaluated (there is no difference between genders). Rats will be randomly assigned to one group, and divided into 3 groups, each group of 10 rats. These procol was based on the guidelines for the use of animals as experimental study subjects onn those described in Guide For The Care And Use Of Laboratory Animals 8a Edition [16] and the WMA Statement on Animal use in Biomedical Research.

Surgical procedures were performed using a microscope with a magnification 6X. And with microsurgical instruments to visualize the epigastric vessels and perforating arteries of the muscle, which will be preserved only side to lift 
TRAM. All TRAM flaps were raised on the right side, preserving the circulation in the upper right epigastric [See Figure 1].

GROUP 1: It is our control group of 10 rats, which was injected only with $0.9 \%$ saline solution at equivalent amount of what was injected in the groups treated with Botulinum Toxin (TBoA), this was injected in the same manner and same location as the TBoA. After being injected, subsequently proceeded to lift the TRAM flap, which was placed above a silicon plate to avoid revascularization on it. After a week (8th post-surgery day) of lifting the flap, the rat was sacrificed for corresponding macroscopic and histopathologic assessments.

GROUP 2: Experimental group of 10 rats where TBOA (1 week pre lifting the flap) was applied at marked points perivascular manner over the entire length of the abdominal flap to sockets of $10 \mathrm{~mm}$, at a dose of $0.5 \mathrm{IU}$ each point with a 100 IU dilution with $4 \mathrm{ml}$ saline $0.9 \%$, with a total dose of each rat of $5 \mathrm{IU}$ (lethal intraperitoneal dose for rats in a rate of 20UI). 8 points and 2 points more about vascular pedicle path were applied in the flap.

After 7 days of applying the TBoA, TRAM flap was performed and a silicon surface [See Figure 2] was placed to avoid revascularization of the flap. A week after raising the flap (day 14) the rat was induced with anesthesia again to take samples of total TRAM flap; the rat was sacrificed and samples were sent to pathology (staining variables were evaluated by means of hematoxylin eosin and Masson: vascularity, ectasia vascularity, inflammation, infection, fibrosis, granulation of the tissue and muscle atrophy.

GROUP 3: Experimental group of 10 rats where the same dosing of TBoA was injected at the same points marked as group 2 but this time it was injected 30 min before the flap was taken. Similarly a surface of silicon was left over the flap

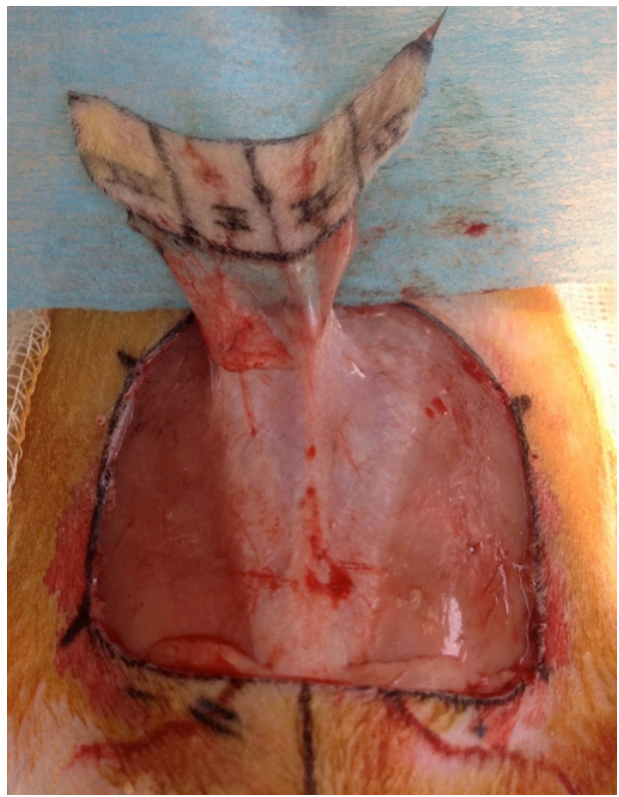

Figure 1. TRAM flap lifting. It can be seen how the flap's circulation depends only on perforating arteries of the right superior epigastric artery. 


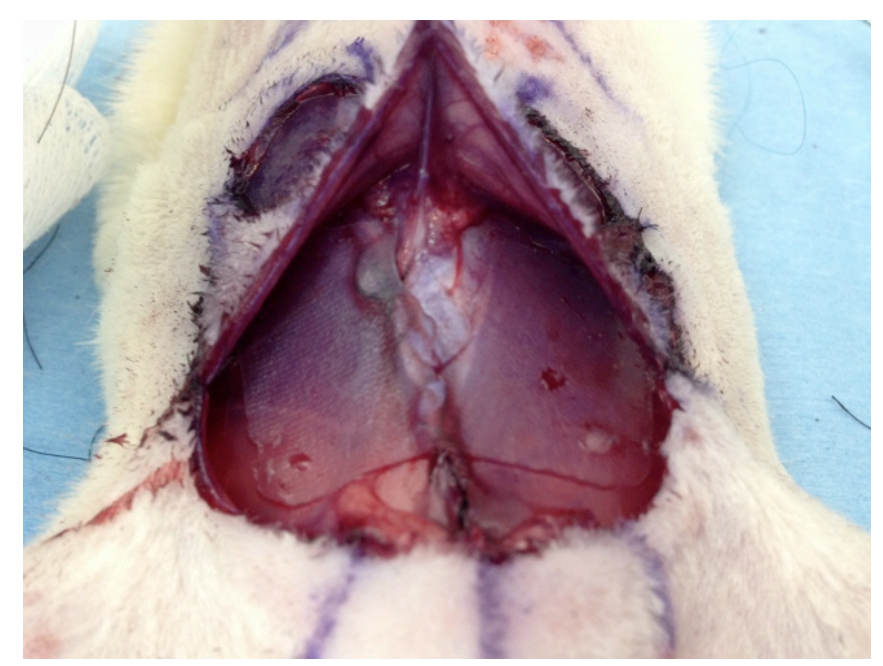

Figure 2. Placing the silicone plaque before closing; to avoid revascularization of the flap.

and the same simple stiches of non-absorbable suture in all quadrants and subsequently suture was performed on the skin A week after being lifted the flap, the same sampling procedure, sacrificing the rat to take samples of the flaps, which will be carried histopathologic evaluation was performed [See Figure 3].

The program SPSS version 20 was used for the statistical evaluation. A numerical value was given to each of the variables $($ mild $=1$ Moderate $=2$ Severe $=$ 3 ), and for the group of vascular ectasia (absent $=0$, present $=1$ ) in order to be valued in the system.

\section{Results}

Flaps were clinically evaluated the eight-day after the uprising, evaluating the degree of necrosis of each one and of viable tissue. A measurement with a millimeter scale with transparent acetate gridded to a scale of $4 \times 4 \mathrm{~mm}$ was done. With this, more accurate measurements were obtained to get the percentage $\%$ of the flap's surface showing viability data and flap's surface showing necrosis data.

Being the group of saline solution $0.9 \%$ (Group 1) the one suffering more percentage of necrosis and the group of transsurgical botulinum toxin the one suffering the lowest percentage of necrosis. When the average of necrosis among the three groups was compared, a significant difference between the saline solution group with $27.7 \% \pm 5.2$.

\section{Histological results:}

Samples of healthy rats abdominal wall, was denominated as Control 0. This sample was taken as the baseline measurement to perform comparative analysis between the 3 groups with TRAM flap: Group 1: 0.9\% saline solution, group 2: Presurgical TBoA, group 3: trans surgical TBoA.

against the group of pre surgical TBoA $11.9 \pm 2.5 \mathrm{p}<0.05$ and against trans-surgical TBoA $7 \% \pm 3.1 \% \mathrm{p}<0.05$ was found.

When making a comparison between group 1 of saline solution against the 


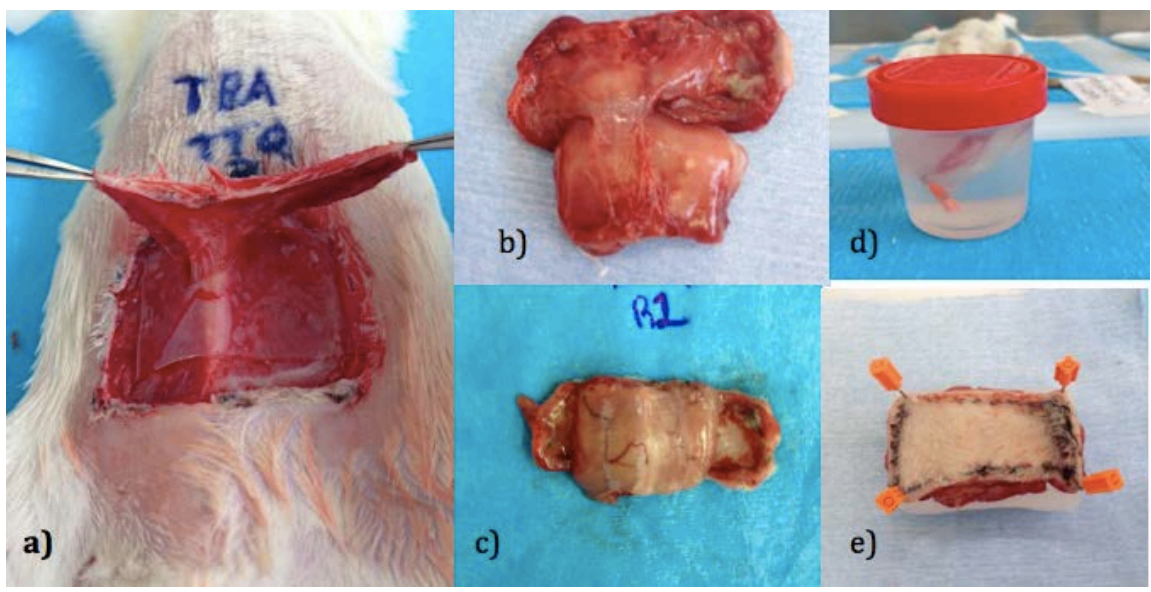

Figure 3. (a) Removal of the TRAM flap in the first postoperative week. (b) surgical piece. (c) back flap. (d) the flap is set in a paraffin block. (e) The flap is placed in flask with Formaldehyde for 24 hours to fix the sample.

group 2 of presurgical Botulinum toxin it was found: increased vascularity in group 2 TBoA compared to saline with $\mathrm{p}=0.000011$ statistically significant [See Figure 4].

Comparing vascular ectasia between these same two groups, TBoA group showed increased vascular ectasia than the saline group $\mathrm{p}<0.05$. As fibrosis, inflammation and granulation tissue there was no statistically significant difference at $\mathrm{p}=0.6$.

It was found that the group of trans-surgical TBoA showed increased vascularity compared with saline at $\mathrm{P}<0.05$, also the group of TBoA showed increased vascular ectasia with $\mathrm{p}<0.05$. Inflammatory tissue was greater in the group of saline solution $0.9 \%$ than in the group of TBOA with a $\mathrm{p}<0.001$. Granulation tissue was greater in the group of TBoA than in saline solution with a $P$ $<0.01$. Muscle atrophy was also higher in the group treated with TBOA than in the saline group $\mathrm{P}<0.05$ statistically significant.

By comparing the degree of muscle atrophy between these same two groups, greater atrophy was observed in the group of TBoA presurgical comparatively with that of transsurgical TBoA this difference no statistically significant at $\mathrm{p}=$ 0.8 .

When the average necrosis among the three groups was compared there was a significant difference between the saline group with $27.7 \% \pm 5.2 \%$ against the group of pre surgical TBoA $11.9 \pm 2.5$ with a $\mathrm{p}<0.05$ and against transsurgical $\mathrm{TBoA} 7 \% \pm 3.1 \%$ with a $\mathrm{p}<0.05$. Finding lower percentage of necrosis in group 3 [see Table 1].

\section{Complications}

The most common complications presented the 3 groups was the seroma and partial dehiscence of sutures. Seroma formation was presented in a total of 19 rats $(63.3 \%)$ of the 30 rats tested. Group 1 presented a total of 4 rats with seroma. Group 2 the total of 7 rats presented seroma. And in group 3 eight rats with seroma. By analyzing these values none were statistically significant. 


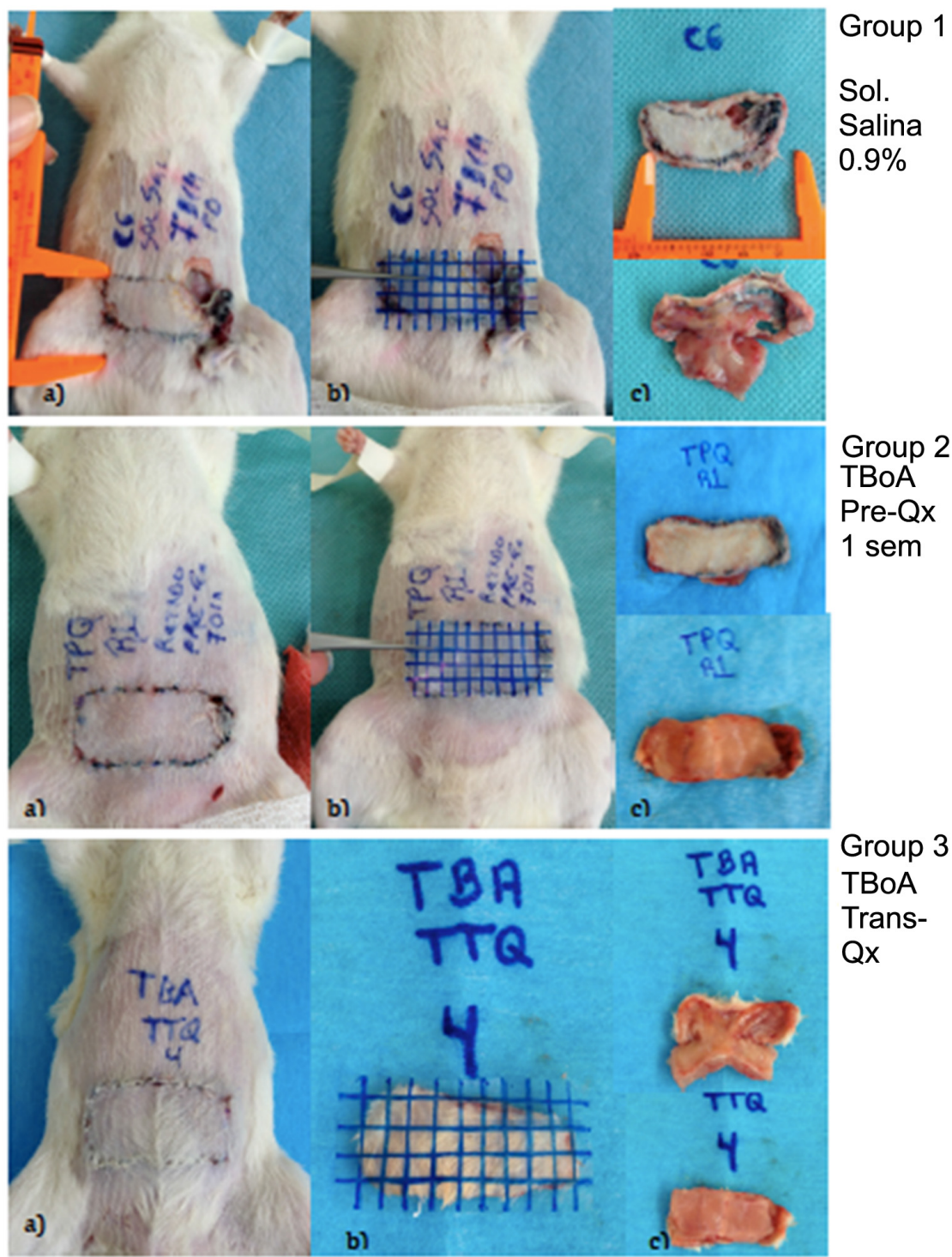

Figure 4. Study groups are shown from top to bottom: Group 1 (saline solution $0.9 \%$, Group 2 (presurgical TBoA), Group 3 (Trans surgical TBoA). (a) Shows the flaps of the 3 groups in the 8th day before dissecting them for histopathological study, areas of necrosis are observed. (b) Measurement by millimetric grid of transparent acetate sheet to calculate the area of necrosis and get percentages. Views of the dissected flap and (front and behind).

Table 1. The mean percentage of necrosis presented in each group. SD: significant difference between groups. $\mathrm{P}$ is considered statistically significant when value is lower than 0.05 .

\begin{tabular}{cccc}
\hline & $\begin{array}{c}\text { Group 1 } \\
\text { Sun. Saline 0.9\% }\end{array}$ & $\begin{array}{c}\text { Group 2 } \\
\text { pre TBoA }\end{array}$ & $\begin{array}{c}\text { Group 3 } \\
\text { Trans TBoA }\end{array}$ \\
\hline Mean & 27.7 & 11.9 & 7 \\
SD & \pm 5.2 & \pm 2.5 & \pm 3.1 \\
$\mathrm{P}^{*}$ & 0.05 & 0.041 & $0.032^{\star}$ \\
\hline
\end{tabular}

*The lower percentage of necrosis was found in the group with trans operatory TBoA. 
Seromas were drained with aseptic technique, most of them did not show evidence of infection, the liquid obtained was a serous liquid nonpurulent, except in two cases in group 1 ( $0.9 \%$ saline) which did show evidence of infection (purulent and turbid liquid).

Another complication presented was infection of the flap, which was more common in group 1 ( $0.9 \%$ saline), with a total of 9 rats compared with the rats of group 2 only with infection 2 rats and group 3 only 1 rat presented infection. The infection rate was higher in the saline group than in the groups treated with TBoA. Most were for Actinomyces infections, and some infected with fungi on the type of candida sp.

\section{Analysis}

Statistical analysis was performed using SPSS version 20 (SPSS, INC., Chicago, ILL). A descriptive evaluation with inferential statistics with Student t-test for independent variables, Chi2 and Fisher exact test to values below 5. Considered statistically significant value $\mathrm{p}<0.05$ for all tests was considered. Results are presented as mean \pm standard deviation.

Descriptive analysis was performed in each of the nominal and ordinal variables, they will be described with simple frequency (n) and relative (\%) and for quantitative variables measures of central tendency (mean or median) and dispersion (standard deviation were used and ranges).

They were classified 3 groups of rats: Group 1 0.9\% saline solution, Group 2 pre surgical TBoA (1 week before lifting the flap), and trans surgical (applied at the time of surgery).

\section{Discussion}

Currently Botulinum Toxin has been used as treatment in a diverse range of pathologies, both for their neuromuscular effect, and its vasoactive effect [17]; however we believe that the broad spectrum of attributes that has this toxin has not yet been completely well defined, so it is still carrying out studies to define each of these attributions and potential beneficial effects to treat different types of diseases or to help improve the vascularity of certain tissues [6]. Vasodilatation is now the center of attention, causing a radical change in its current indications especially regarding the survival of the tissue used in plastic and reconstructive surgery.

This experimental study is particularly important to evaluate the protective action of botulinum toxin type A to necrosis in myocutaneous flaps or flaps compounds by more than one tissue type. Affecting not only the circulation to the vascular pedicle of these flaps, but throughout the microvasculature located throughout the flap.

Historical data of the vasodilator effect of TBoA, demonstrated by Van Beek [17] and Neumeister [14] in vasospastic disorders as well as those reported by Clemens [18] who uses the TBoA to prevent anastomotic thrombosis decreasing vasospasm. Although Arnold-Merrit [19] does not find significant differences in 
a vascular study on the feasibility of applying perivascular TBoA to flaps, W. Yoo [20] through doppler flowmetry shows an increased blood supply in both distal segment, and the middle and proximal with the application of TBoA ( $\mathrm{p}<$ $0.05)$.

Our experimental study assesses the beneficial effect of botulinum toxin type on pedicle musculocutaneous flaps, which has not been shown in previous studies have only been conducted with random skin flaps such as develops Young [21]. With this study we tried to improving the circulation of a compound flap not only include skin but the one that had more of a tissue as is the case of TRAM, which is composed of skin, fat, and muscle and its blood supply type were not random as in the case of the aforementioned skin flaps; but circulation outside dependent on a single vascular pedicle in this case is given by the superior epigastric artery and perforating of the same that will nourish the skin and more superficial tissues.

Another important factor to evaluate in our study was the timing in applying the botulinum toxin, considering that the greatest effect of the toxin in the neuromusclar layer is after 7 days. But it's more toxin action at the vascular level and lower necrosis was the group with transsurgical botulinum toxin.

We found significant difference in the percentage of flap necrosis using TBoA vs saline solution (9\%). In group 1 necrosis was present in $27.7 \% \pm 5.2 \%$ against the group of pre surgical TBoA that was $11.9 \pm 2.5 \mathrm{p}<0.05$. And against transsurgical TBOA that was $7 \% \pm 3.1 \%(\mathrm{p}<0.05)$. Corroborating therefore the effect of TBoA as mentioned Young [19].

Finally, like other authors as Arnold [13], it is shown that clinical results correlate with histological outcomes an increase in the diameter of the vessels and vascular ectasia in histologic sections. When performing a statistical comparison between the saline solution-treated group and the groups which was used with TBoA a statistically significant difference with $\mathrm{p}<0.05$ for both increased vascularity to ectasia or vascular dilation found. The two treated groups TBoA (group 2 and 3) were statistically more vascularized than the control group, however when comparing these same two groups including the group that showed more vascularization and vascular ectasia was the group with transsurgical TBoA (group 3) with $\mathrm{p}=0.8$, which is not statistically significant.

As for complications they were observed in the study, which were infection and seroma. We found that most rats showed infection were in the saline solution-treated group and this could be explained by a higher percentage of flap necrosis, which favored them sometimes dehiscence in the necrotic side of the flap and thus facilitating the entrance of pathogenic microorganisms into it. Most of the infections were caused by strains of Actinomyces sp and there were some cases of superinfection by fungi (Candida sp).

\section{Conclusions}

Ensuring the blood supply to a flap before dissecting it reduces the risk of infec- 
tion, necrosis and loss of the flap, which increases the time of hospital stay and therefore its costs. The delay phenomenon allows us to improve the blood supply and with this study we were able to demonstrate in this experimental model that TBoA allows performing a non-surgical delay effect of a pedicled musculocutaneous flap; inhibiting initial vasoconstriction after the dissection and subsequently maintaining sustained vasodilatation by sympathetic denervation of blood vessels.

Based on these results and having already demonstrated its vasoactive function in flaps, we would like to continue comparing botulinum toxin with other mechanisms described above to improve the vasculature of a flap. However we consider that this study allow to establish a new pattern in the therapeutic use of botulinum toxin, we develop this experimental study based on the basis of other previous studies which describe effects of the toxin as a vascular modulator. But yet none of these studies indicated whether these beneficial effects on the vasculature may improve survival of a compound flap as is the case in TRAM flap. Thus we show that the toxin not only has a local effect in the vascular pedicle forming ectasia and dilatation; but also promotes the growth and vascular proliferation of microvasculature in flap and also in the outer layers of it.

\section{Conflicts of Interest}

The authors declare no conflicts of interest regarding the publication of this paper.

\section{References}

[1] Qi, Z., Gu, Y., Kim, D., Hiura, A., Sumi, S. and Inoue, K. (2007) The Effect of Fibrin on the Survival of Ischemic Skin Flaps in Rats. Plastic and Reconstructive Surgery, 120, 1148-1155. https://doi.org/10.1097/01.prs.0000279524.05541.5b

[2] Rinker, B., Fink, B., Barry, N., Fife, J. and Milan, M. (2010) The Effect of Calcium Chanel Blockers on Smoking-Induced Skin Flap Necrosis. Plastic and Reconstructive Surgery, 125, 866. https://doi.org/10.1097/PRS.0b013e3181ccdc60

[3] Uema, D., Orlandi, D., Freitas, R., Rodgério, T., Yamamura, Y. and Tabosa, A. (2008) Effect of Electroacupuncture on DU-14 (Dazhui), DU-2 (Yaoshu), and Liv-13 (Zhangmen) on the Survival of Wistar Rats' Dorsal Skin Flaps. Journal of Burn Care \& Research, 29, 353. https://doi.org/10.1097/BCR.0b013e31816679a6

[4] Drever, J.M. (1977) The Epigastric Island Flap. Plastic and Reconstructive Surgery, 59, 343-346. https://doi.org/10.1097/00006534-197703000-00005

[5] Hartrampf, C.R., Scheflan, M. and Black, P.W. (1982) Breast Reconstruction with a Transverse Abdominal Island Flap. Plastic and Reconstructive Surgery, 69, 216-225. https://doi.org/10.1097/00006534-198202000-00006

[6] McCraw, J.M., Dibbell, D.G. and Carraway, J.H. (1977) Clinical Definition of Independent Myocutaneous Vascular Territories. Plastic and Reconstructive Surgery, 60, 341-352. https://doi.org/10.1097/00006534-197760030-00003

[7] Redaelli, A. and Forte, R. (2003) Botulinum Toxin Dilution: Our Technique. Journal of Cosmetic \& Laser Therapy, 5, 218. https://doi.org/10.1080/14764170310021841

[8] Gutiérrez, S.E., et al. (2004) Retardo químico del colgajo TRAM en ratas. Cirugia 
Plastica, 14, 120-125.

[9] Alcolea López, J.M. (2011) Actualización sobre aplicaciones de la toxina botulínica en estética facial. Cirugía Plástica Ibero-Latinoamericana, 37, 81.

https://doi.org/10.4321/S0376-78922011000100012

[10] Erbguth, F. (2008) From Poison to Remedy: The Chequered History of Botulinum Toxin. Journal of Neural Transmission, 115, 559. https://doi.org/10.1007/s00702-007-0728-2

[11] Currá, A. and Berardelli, A. (2009) Do the Unintended Actions of Botulinum Toxin at Distant Sites Have Clinical Implications? Neurology, 72, 10. https://doi.org/10.1212/01.wnl.0000345010.98495.fc

[12] Matic, D., Lee, T., Wells, R. and Gan, B. (2007) The Effects of Botulinum Toxin Type A on Muscle Blood Perfusion and Metabolism. Plastic and Reconstructive Surgery, 120, 1823. https://doi.org/10.1097/01.prs.0000287135.17291.2f

[13] Chenwang, D., Shiwei, B., Dashan, Y., et al. (2009) Application of Botulinum Toxin Type A in Myocutaneous Flap Expansion. Plastic and Reconstructive Surgery, 124, 1450-1457. https://doi.org/10.1097/PRS.0b013e3181b989be

[14] Neumeister, M., Chambers, C., Herron, M., et al. (2009) Botox Therapy for Ischemic Digits. Plastic and Reconstructive Surgery, 124, 191.

https://doi.org/10.1097/PRS.0b013e3181a80576

[15] Arnold, P., Campbell, C., Rodeheaver, G., Merrit, W., Morgan, R. and Drake, D. (2009) Modification of Blood Vessel Diameter Following Perivascular Application of Botulinum Toxin A. Hand, 4, 302-307. https://doi.org/10.1007/s11552-009-9169-8

[16] National Research Council (2011) Guide for the Care and Use of Laboratory Animals: Eighth Edition. The National Academies Press, Washington, DC.

[17] Beek, A., Lim, P., Gear, A. and Pritzker, M. (2007) Management of Vasospastic Disorders with Botulinum Toxin A. Plastic and Reconstructive Surgery, 119, 217. https://doi.org/10.1097/01.prs.0000244860.00674.57

[18] Clemens, M., Higgins, J. and Wilgis, E. (2009) Prevention of Anastomotic Thrombosis by Botulinum Toxin A in an Animal Model. Plastic and Reconstructive Surgery, 123, 64. https://doi.org/10.1097/PRS.0b013e3181904c31

[19] Arnold, P., Merritt, W., Rodeheaver, G., Campbell, A., Morgan, R. and Drake, D. (2009) Effects of Perivascular Botulinum Toxin A Application on Vascular Smooth Muscle and Flap Viability in the Rat. Annals of Plastic Surgery, 62, 463. https://doi.org/10.1097/SAP.0b013e3181903252

[20] Kim, Y.S., Roh, T., Lee, W., Yoo, W. and Tark, K. (2009) The Effect of Botulinum Toxin A on Skin Flap Survival in Rats. Wound Repair and Regeneration, 17, 411. https://doi.org/10.1111/j.1524-475X.2009.00477.x

[21] Hantash, B. and Gladstone, H. (2007) A Pilot Study on the Effect of Epinephrine on Botulinum Toxin Treatment for Periorbital Rhytides. Dermatologic Surgery, 33, 461-468. https://doi.org/10.1111/j.1524-4725.2007.33094.x 